\title{
Impacts of Climate Change on Japanese Radish in Ichihara and Their Potential Implications
}

\author{
Kurasaka Hidefumi, Teruya Sekine, Sashiro Murayama, Takahide Aoyagi, Karen Mitamura, and Xiang
} $\mathrm{Li}$

\begin{abstract}
This study is a part of research outcomes of JST/RISTEX national project in Japan. Impacts of climate change on Japanese Radish in Ichihara city, Chiba prefecture, Japan, are analyzed. The model incorporates the consideration of both climate variable and technology improvement. Diverting from the public recognition that agricultural production would be significantly damaged by climate change, we find that with the help of technology improvement Japanese radish yields could still increase along with an increase in temperature over the next 30 years. Along with a further increase in temperature, increasing ratio of Japanese radish yield in 2040 to that in 2012 decreases. Such results reflect the sensitive responses of Japanese radish to the changing environment. The results imply the adaptability of local agricultural production to climate variation and the importance of technology improvement to the production of Japanese radish. Stronger adaptiveness to the increased temperature, combined with other adaptation measures such as policy support, may play key roles in restructuring agricultural sector and improving the overall competitiveness of Japanese agriculture. In such a case, the TPP would become a chance rather than risks to the local farmers. All in all, further emphasis should be put on agricultural research.
\end{abstract}

Index Terms - Climate change, Japanese radish in Ichihara, technology improvement, temperature, adaptability, the TPP.

\section{INTRODUCTION}

Food security is a key word to human beings as our survival, socioeconomic growth, culture and health are linked to it. Polarization structure of world crop production has divided countries to be either net importers or net exporters, making agricultural products special "strategic weapons" in international negotiation [1]-[3].

Regardless of what industries are strong or weak at local level, country level, or regional level, all the people in the world need to eat in order to survive. Thus, for any country, ensuring sustainable development of agriculture is crucially important. Since the time of Industrial Revolution in the 19th century, humans have increased their influences on global climate system, which in turn has impacted different sectors in various ways [1]- [4]. Agricultural sector specially is sensitive to the changes in the external environment [1]-[3]. In the context of national food security and the TPP, analyzing and simulating the impacts of climate change on agricultural products is extremely important.

In this study, Japanese Radish (Raphanus sativus)

Manuscript received October 13, 2015; revised December 29, 2015.

The authors are with Chiba University, 263-8522 Japan (e-mail: xiangli22@chiba-u.jp). produced in Ichihara, Chiba prefecture, Japan, is purposely chosen for analysis for the following reasons. First, among different varieties of agricultural products, the average of calorie-based self-sufficiency ratios of vegetables is higher, around $79 \%$ in 2013, next to that of rice and eggs [5]. According to official statistics of Japan, Chiba prefecture, next to Hokkaido, is the second largest Japanese radish producer in Japan [5]. In 2013, 158,100 tons of Japanese radish is produced in Chiba prefecture [6]. Given the backdrop that the average calorie-based self-sufficiency rate in Japan is only about $39 \%$ in 2014 , the relatively high self-sufficiency rate of Japanese radish could mean a lot to Japan such as its potential competiveness in the face of the TPP [7].

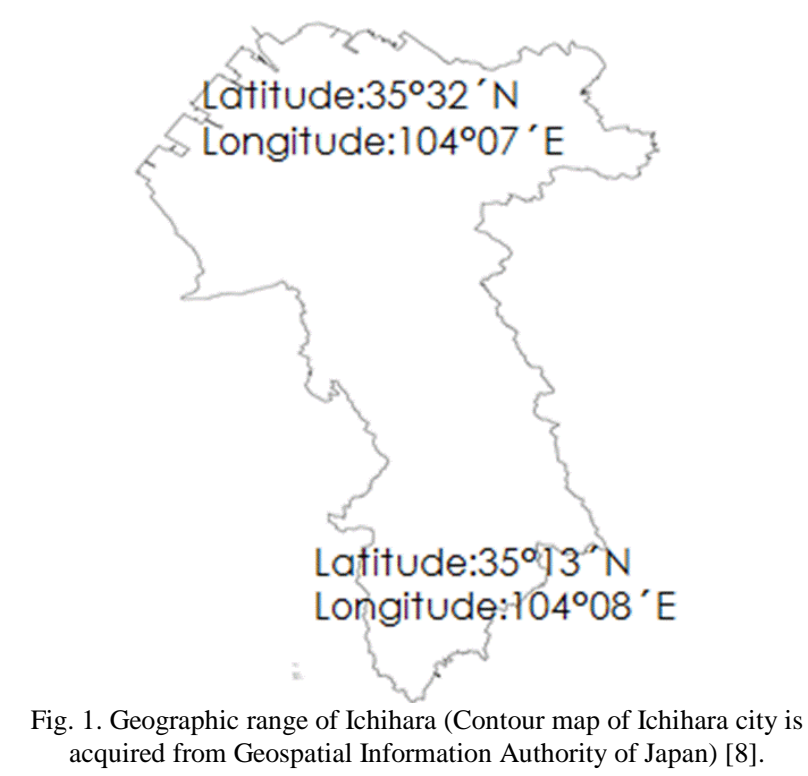

Secondly, Ichihara has established Anesaki Japanese radish brand, making Japanese radish a representative agricultural crop at the local level. Fig. 1 illustrates the geographic range of the city, where the latitude ranges from $35^{\circ} 13^{\prime}$ north to $35^{\circ} 32^{\prime}$ north and the longitude ranges from $104^{\circ} 07^{\prime}$ east to $104^{\circ} 08^{\prime}$ east. Furthermore, it can also be found that most agricultural crops share a common characteristics. They are sensitive to the environmental changes. Thus, it is meaningful to understand the impacts of climate change on Japanese radish.

Many past studies have analyzed Japanese radish from the perspectives of plant biology and soil science [9]-[13]. Under experimental conditions, soil temperature is controlled and adjusted to examine its effects on the root system. In another case, Chen (2010) focused on the perspective of atmospheric gases [14]. The study analyzed how ambient-level gas-phase 
peroxides affected the growth of Japanese radish. Other studies have analyzed the medical effects on Japanese radish [15]-[16]. For example, a study conducted by Taniguchi (2006) examined the medical effects of Japanese radish sprout on diabetes [16].

Though many past studies have analyzed Japanese radish from different perspectives, their analysis focuses are on spring Japanese radish variety. However, harvested amount of autumn-winter Japanese radish variety in 2013 has been found to account for about $67 \%$ of the total harvested amount in Japan. Thus, it is meaningful to include the consideration of both the spring variety and the autumn-winter variety. Furthermore, despite the biological perspective of Japanese radish is carefully analyzed, the potential impact of climatic change on Japanese radish with the consideration of technology improvement has not been well analyzed.

Given above information and the fact that local economy depends on the health of agriculture for its further development, it is critically important to understand the impacts of climate change on Japanese radish. Through analysis, we find that with the help of technology improvement Japanese radish could still increase along with an increase in temperature over the next 30 years. Accompanying with a further increase in temperature, the increasing ratio of Japanese radish yield in 2040 to that in 2012 decreases, reflecting the sensitivity of Japanese radish to the changes in temperature. Such results are different from the public recognition that agricultural production would be significantly damaged by climate change. The results also imply the possible adaptability of local agricultural production to climate variation. The results also illustrate the importance of technology improvement to the production of Japanese radish.

Stronger adaptiveness to the increased temperature, combined with other adaptation measures such as policy support, may play key roles in restructuring agricultural sector and improving the competitiveness of Japanese agriculture. In such a case, the TPP would become a chance rather than risks to the local farmers. All in all, this study is extremely meaningful in the context of food security, regional revitalization and economic growth, and the potential adaptability to the TPP.

\section{MATERIALS AND MethodOlOGY}

In this study, temperature variable and technology improvement variable are simultaneously incorporated in the model to analyze and simulate the effects of climate change on Japanese radish as depicted in the Fig. 2. In most cases, " $\mathrm{CO}_{2}$ fertilizer effect" is examined under the controlled environment where high concentration of $\mathrm{CO}_{2}$ is released to analyze its effects on agricultural production. However, in the natural environment, atmospheric carbon dioxide concentration increases gradually, not abruptly. Hence, the effects of changes in atmospheric carbon dioxide concentration on agricultural crops in the natural condition is not obvious. Furthermore, the interactions of $\mathrm{CO}_{2}$ with other environmental variables are still debated among scientists [1]. Thus, we assume there is no " $\mathrm{CO}_{2}$ fertilizer effect" and $\mathrm{CO}_{2}$ variable is not directly included in the model. Rather, it is indirectly utilized for simulating the future climate change impacts on Japanese radish in three climate change scenarios.

In this study, the following model is used.

$$
Y=\beta_{0}+\beta_{1} T I+\beta_{2} T-\beta_{3} T^{2}
$$

where $Y$ represents Japanese radish yield (100 tons/ha), TI indicates technology improvement (linear trend term), $T$ refers to the average temperature over the sensitive growing stage of both spring Japanese radish variety and autumn-winter Japanese radish variety $\left({ }^{\circ} \mathrm{C}\right)$ in the equation (1) (see Fig. 2) [3].

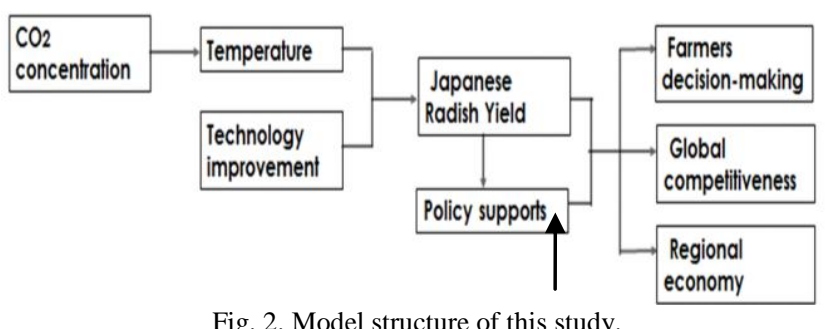

Time series vegetable data at the levels of cities, towns, and villages in Ichihara are only available for a limited time. Thus, data on planted area (hectares) and harvested amount (tons) of Japanese radish over the period from 1994 to 2004 in Ichihara city are collected at first [17]. Given the background that year to year agricultural production does not change so much, we assume the ratio of Ichihara city Japanese radish production to Chiba prefecture Japanese radish production is relatively stable. For estimation, we also collect data on planted area (hectares) and harvested amount (tons) of Japanese radish in Chiba prefecture over the period from 1994 to 2012 [18]. For both planted area and harvested amount, we have collected data of Ichihara city divided by that of Chiba prefecture to calculate the ratios. To ensure consistency, we then calculate the five-year average ratios (2000-2004) for both planted area and harvested amount and use the fixed ratios in the later calculation process. To estimate planted area and harvested amount in Ichihara over the period from 2005-2012, we separately multiply planted area and harvested amount in Chiba prefecture over period from 2005-2012 to the calculated ratios. By having harvested amount divided by planted area, we acquire time series Japanese radish yield data over period of 2005 to 2012.The already acquired data over period of 1994 to 2004 and the calculated data are combined together and are then convert to the units of 100 tons/ha for modelling.

In contrast, climate data are available at designated climate stations. Thus, we choose climate observation point at Ushiku (latitude: $35^{\circ} 23.8^{\prime}$ north, longitude: $140^{\circ} 8.9^{\prime}$ east) that is close to Ichihara city within the Chiba prefecture for analysis. According to Ichihara report, the growing season of autumn-winter Japanese radish variety covers over the months from October to the early February in the next year, and the growing season of spring Japanese radish variety covers months from mid-February to early June [19]. To analyze the overall effects of climate change on Japanese radish, average monthly temperature from October to June over the period of 1994 to 2012 are collected from Ushiku 
climate observation point [20]. Then, collected average temperature data in each year are averaged to acquire average temperature that corresponds to the sensitive growing stage of Japanese radish.

Similar to the method described in $\mathrm{Li}^{\prime}$ paper, technology is assumed to improve at a stable rate over the analysis period and a linear time trend as a proxy of it is utilized in the function [1].

The estimated Japanese radish results in turn could become useful information for farmers in making their future production decision. The results could also help policy-makers and the government design better policies. The estimated results as a guiding index could also be utilized with policies to design better strategies to increase its global competitiveness (see Fig. 2).

\section{RESULTS}

With the processes described in the earlier section, the effects of climate change on Japanese radish yields are first analyzed (see Table I). Through analysis, we find the coefficient of technology improvement variable in the model is 0.002 . Incorporation of this variable in the model is critically important as technology plays a key role in the agricultural sector. When temperature is allowed to increase $1^{\circ} \mathrm{C}$ from the current level and technology is set to improve continuously, Japanese radish yield in 2040 is simulated to be 0.65 (100tons/ha). In another case where temperature is allowed to increase $1^{\circ} \mathrm{C}$ from the current level, but the technology variable is controlled to be unchanged from the current level, Japanese radish yield in 2040 is predicted to be 0.59 (100tons/ha). The differences between technology improved case and stabilized case indicate the importance of technology variable to Japanese radish production. In terms of $\mathrm{R}$ squared value, previous studies that analyze agricultural crops showed a wide range of possible values. In our study, it is 0.46 (see Table I).

TABLE I: ANALYSIS RESULTS IN ICHIHARA CITY (DATA OVER 1994-2012 ARE UTILIZED IN THE MODEL)

\begin{tabular}{ll}
\hline $\begin{array}{l}\text { Explained variable (Japanese radish } \\
\text { yields) }\end{array}$ & Ichihara City \\
Explanatory variables & Coefficients (t-values) \\
Constant & $-9.367(-3.01)$ \\
$T I$ & $0.002(2.795)$ \\
$T$ & $0.924(2.07)$ \\
$T^{2}$ & $-0.04(-2.07)$ \\
R-squared & 0.46 \\
Adjusted R squared & 0.35 \\
D.W. & 2.16
\end{tabular}

In this study, Japanese radish yields over the period of 2013 to 2040 are also simulated and predicted with three climate scenarios (see Fig. 3). They are 1) optimistic warmer scenario, 2) moderate scenario and 3) pessimistic scenario. Similar to the method described in Li's paper, potential changes in $\mathrm{CO}_{2}$ concentration and temperature reported in the IPCC reports are utilized to predict the potential effects of climate change on Japanese radish over the period of 2013 to 2040 [1]. Given the fact that temperature fluctuates from year to year, the average of temperature from 2008 to 2012 are calculated and utilized as the current level temperature in the analysis. In each of three scenarios, temperature is set to increase $0.32^{\circ} \mathrm{C}$, $0.72^{\circ} \mathrm{C}$ and $1.32^{\circ} \mathrm{C}$ separately from the current level.

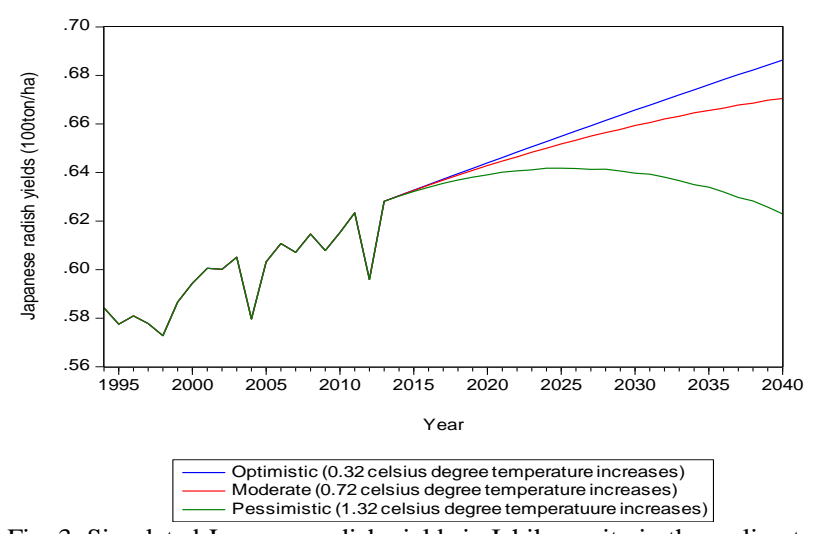

Fig. 3. Simulated Japanese radish yields in Ichihara city in three climate change scenarios over the period of 2013 to 2040.

TABLE II: RATIOS OF ICHIHARA JAPANESE RADISH YIELDS IN 2040 TO THAT

\begin{tabular}{llll}
\multicolumn{3}{c}{ IN 2012 } & \\
\hline & $\begin{array}{l}\text { Optimistic } \\
\text { climate } \\
\text { scenario }\end{array}$ & $\begin{array}{l}\text { Moderate } \\
\text { climate } \\
\text { scenario }\end{array}$ & $\begin{array}{l}\text { Pessimistic } \\
\text { climate scenario }\end{array}$ \\
\hline $\begin{array}{l}\text { Ratios of Japanese } \\
\text { radish yields } \\
(2040 / 2012)\end{array}$ & 1.15 & 1.13 & 1.05 \\
\hline
\end{tabular}

Using the model described earlier, we simulate the potential impacts of climate change on Japanese radish over the period of 2013 to 2040 and find that the Japanese radish yields in 2040 increase above the current level in all climate change scenarios (Fig. 3 and Table II). Among three types of climate change scenario, yield shows the best performance in optimistic scenario where temperature increases 0.32 Celsius degree from the current level. Along with a further increase in temperature, increasing ratio decreases. In comparison with the optimistic scenario, ratio of Japanese radish in 2040 to 2012 is lower in the moderate scenario (1.13). The ratio becomes 1.05 in pessimistic scenarios. The results reflect the sensitive responses of Japanese radish to changes in temperature.

For Japanese radish, its optimal growing temperature ranges between 17 to $20{ }^{0} \mathrm{C}$ [21]. While an increase in temperature in the colder autumn and winter is welcome to autumn-winter variety, it could damage the development of spring Japanese radish variety and impact the overall yield.

Interestingly, though the potential changes in temperature could impact the growth of spring Japanese radish variety and affect the overall yield results, the negative impacts of climate change on Japanese radish could be mitigated with the help of continuous technology improvement.

With this variable considered, Japanese radish yield could still be maintained in pessimistic scenario where temperature increases 1.32 Celsius degree from the current level (see Fig. 3 and Table II). Given the backdrop that food is critical to our survival, the mitigating effect of technology variable has significant implications for both the nation and regional economy. 


\section{DISCUSSION}

The estimated results indicate the importance of technology variable in mitigating the negative impacts of climate change on Japanese radish in Ichihara city. Though Japanese radish yields in the city are simulated to increase in all climate change scenarios, further increases in temperature from the current level can still affect the increasing ratio of Japanese radish yield in 2040 to that in 2012. Such results reflect the sensitive responses of Japanese radish to the exterior environment. Furthermore, it is easier to understand that adaptability of local Japanese radish production depends on the continuous improvement in technology.

Estimated results in this study could be utilized for designing better agribusiness model. They could also be used to restructure agricultural industry at the local level to revitalize local economy and regional economy.

\section{CONCLUSION}

Given the backdrop that food is critical to our survival and many farmers at the local level depends on agriculture to support their families, the effects of technology variable in mitigating the potential negative impacts of climate change on Japanese radish is extremely important to both farmers and the nation. From the perspective of on-site practice, management, risk adaptation to climate change, and the long-term sustainability of agriculture, more emphasis should be put on agricultural research as this variable is key to the sustainable development of agriculture.

\section{REFERENCES}

[1] X. Li, T. Takahashi, N. Suzuki, and H. M. Kaiser, "The impacts of climate change maize yields in the United States and China," Agricultural Systems, vol. 104, pp. 348-353, April 2011.

[2] X. Li and N. Suzuki, "Implications of climate change impacts on regional maize production in the United States: Risk mitigation strategies and food security," International Journal of Environmental Science and Development, vol. 4, pp. 446-451, October 2013.

[3] X. Li, T. Takahashi, N. Suzuki, and H. M. Kaiser, "Impact of climate change on maize production in northeast and southwest China and risk mitigation strategies," APCBEE Procedia, vol. 8, pp. 11-20, 2014.

[4] X. Li and C. McMillan, "Corporate strategy and the weather: Towards a corporate sustainability platform," Journal of Problems and Perspectives in Management, vol. 12, issue 2, pp. 200-214, 2014.

[5] Hokuriku Regional Agricultural Administration Office. (2015). Self-sufficiency in Japan. [Online]. Available: http://www.maff.go.jp/hokuriku/kids/tanken/oneself04.html

[6] Official Statistics of Japan. (2015). [Online]. Available: https://www.e-stat.go.jp/SG1/estat/GL08020103.do?_toGL08020103 \&listID $=000001128458 \&$ requestSender $=$ estat

[7] Ministry of Agriculture, Forestry and Fisheries. (2014). Summary of calorie-based self-sufficiency rate in Japan. [Online]. Available: http://www.maff.go.jp/j/zyukyu/zikyu_ritu/pdf/26gai.pdf

[8] Geospatial Information Authority of Japan. (2015). Map. [Online]. Available: http://www.freemap.jp/about_use_map.php

[9] Y. Kano, "Effects of time of high and low soil temperature treatments on the growth of Japanese radish cv. 'Gensuke' and the occurrence of hollow root," Journal of the Japanese Society for Horticultural Science, Vol. 57, pp. 626-632, 1989.

[10] Y. Kano and N. Fukuoka, "Effects of soil temperature on hollowness in Japanese radish (Raphanus sativus L. cv. 'Gensuke')", Scientia Horticulturae, vol. 61, pp. 157-166, 1995.

[11] T. Kawai, M. Hikawa, and T. Fujisawa, "Effects of sowing time, soil temperatures, and shade on internal browning and polyphenol concentration in roots of Japanese Radish," Journal of the Japanese Society for Horticultural Science, vol. 61, pp. 339-346, 1992.
[12] Y. Fujime, N. Okuda, and J. R. Aspuria, "Effects of solution temperatures on root growth in cool season vegetables," Environmental Control in Biology, vol. 30, pp. 177-183, 1992.

[13] C. Cheon, Y. Watanabe, and T. Saito, "An approach to the characterization of varietal difference in inflorescence formation due to vernalization in Radish plants using "Flower Formation Index," Environmental Control in Biology, vol. 42, pp. 305-314, 2004.

[14] X. Chen, M. Aaki, A. Takami, F. Chai, and S. Hatakeyama, "Effects of ambient-level gas-phase peroxides on foliar injury, growth, and net photosynthesis in Japanese radish (Raphanus sativus)," Environmental Pollution, vol. 158, pp. 1675-1679, 2010.

[15] D. C. Willcox, G. Scapagnini, and B. J. Willcox, "Healthy aging diets other than the Mediterranean: A focus on the Okinawa diet," Mechanisms of Ageing and Development, 136-137, pp. 148-162, 2014.

[16] H. Taniguchi, K. Kobayashi-Hattori, C. Tenmyo, T. Kamei, Y. Uda, Y. Sugita-Konishi, Y. Iushi, and T. Takita, "Effect of Japanese Radish (Raphanus sativus) sprout (Kaiware-daikon) on carbohydrate and lipid metabolisms in normal and streptozotocin-induced diabetic rats," Phytotherapy Research, vol. 20, pp. 274-278, 2006.

[17] Official Statistics of Japan. (2015).Vegetable data at the levels of cities, towns and villages. [Online]. Available: http://www.e-stat.go.jp/SG1/estat/List.do?lid=000001075399

[18] Official Statistics of Japan. (2015). Vegetable research. [Online]. Available:

https://www.e-stat.go.jp/SG1/estat/GL08020103.do?_toGL08020103 _\&listID $=000001128458 \&$ requestSender=estat

[19] Ichihara City Industry White Paper. (2014). Agriculture. [Online] Available:

https://www.city.ichihara.chiba.jp/kanko/0205sangyou/sangyo/sangy o26.files/nougyou.pdf

[20] Japan Meteorological Agency. (2015). Past climate data. [Online]. Available: http://www.data.jma.go.jp/gmd/risk/obsdl/index.php

[21] Ministry of Agriculture, Forestry and Fisheries. (2015). Japanese radish. [Online]. Available: http://www.maff.go.jp/j/seisan/kankyo/hozen_type/h_sehi_kizyun/pd f/04180211konsai2.pdf

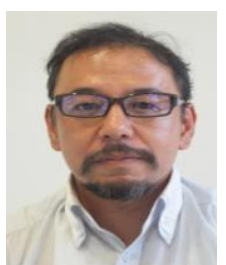

Hidefumi Kurasaka is a professor at Chiba University in Japan. He graduated from the University of Tokyo with the degree of bachelor (bachelor of economics) in 1987. He was a deputy director of the environmental agency of the Japanese government, and a visiting researcher at the Maryland University in the United States. He now works as a professor in the field of environmental policy and ecological economics at the Graduate School of Humanities and Social Sciences of Chiba University. He published various papers and books in the field of environmental policy and ecological economics such as environmental policy 3rd ed. (2014) and ecological economics (2005).

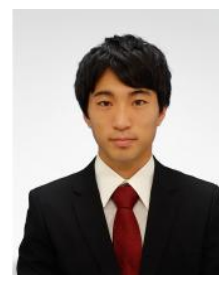

Teruya Sekine is a third-year student. He belongs to the Faculty of Law, Politics and Economics at Chiba University. He is interested in Japanese political history and history of foreign diplomacy and is studying them.

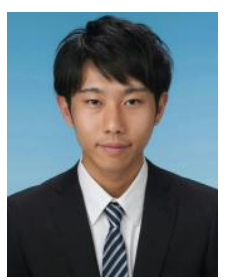

Sashiro Murayama is a fourth-year student. He belongs to the Faculty of Law, Politics and Economics at Chiba University.

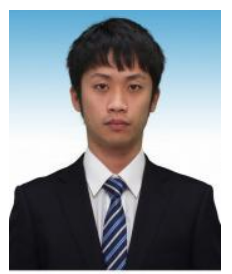

Takahide Aoyagi belongs to the department of Social Science in Chiba university. He analyzes the present situations of trans-pacific trade. His articles are published in "MATCHA", a web magazine that provides Japanese culture with foreigners. 


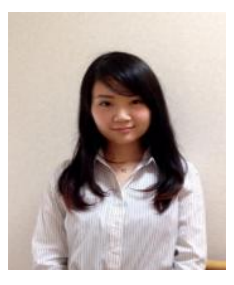

Karen Mitamura is a fourth-year student. She belongs to the Faculty of Law, Politics and Economics at Chiba University.

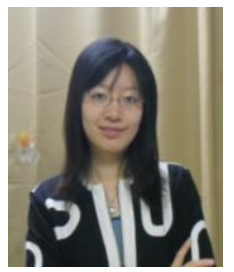

Xiang $\mathbf{L i}$ is an assistant professor belonging to the Faculty of Law, Politics and Economics, Chiba University, Japan. She graduated from the University of British Columbia, Canada, with the degree of bachelor of science for natural resources conservation in 2007. She received her science master degree in 2010 and the Ph.D. degree in 2013 for international environmental economics at the University of Tokyo in Japan. She was a DBA director at the Graduate School of International Corporate Strategy of Hitotsubashi University, a national University in
Japan. She worked as an assistant professor at the Academy for Co-creative Education of Environment and Energy Science of Tokyo Institute of Technology, another national University in Japan. Now, she works as an assistant professor at Chiba University, another national university in Japan, and now belongs to the faculty of Law, Politics \& Economics. Among Li's published refereed academic articles and issued patents, one that focused on agricultural production and climate change adaptation strategy has been highlighted and introduced by Nature Climate Change Journal (Nature Publishing Group) (February, 2011). 